\title{
Probe of Radiant Flow on Temperature-Dependent Viscosity Models of Differential Type MHD Fluid
}

\author{
Azad Hussain (D), ${ }^{1}$ Sobia Akbar, ${ }^{1}$ Lubna Sarwar, ${ }^{1}$ and Sohail Nadeem ${ }^{2}$ \\ ${ }^{1}$ Department of Mathematics, University of Gujrat, Gujrat 50700, Pakistan \\ ${ }^{2}$ Department of Mathematics, Quaid-i-Azam University, Islamabad 44000, Pakistan \\ Correspondence should be addressed to Azad Hussain; azad.hussain@uog.edu.pk
}

Received 20 April 2020; Revised 15 September 2020; Accepted 25 October 2020; Published 7 November 2020

Academic Editor: Giovanni Lancioni

Copyright ( $\odot 2020$ Azad Hussain et al. This is an open access article distributed under the Creative Commons Attribution License, which permits unrestricted use, distribution, and reproduction in any medium, provided the original work is properly cited.

This paper numerically investigates the combined effects of the radiation and MHD on the flow of a viscoelastic Walters' B liquid fluid model past a porous plate with temperature-dependent variable viscosity. To study the effects of variable viscosity on the fluid model, the equations of continuity, momentum with magnetohydrodynamic term, and energy with radiation term have been expanded. To understand the phenomenon, Reynold's model and Vogel's model of variable viscosity are also incorporated. The dimensionless governing equations are two-dimensional coupled and highly nonlinear partial differential equations. The highly nonlinear PDEs are transferred into ODEs with the assistance of suitable transformations which are solved with the help of numerical techniques, namely, shooting technique coupled with Runge-Kutta method and BVP4c solution method for the numerical solutions of governing nonlinear problems. Viscosity is considered as a function of temperature. Skin friction coefficient and Nusselt number are investigated through tables and graphs in the present probe. The behavior of emerging parameters on the velocity and temperature profiles is studied with the help of graphs. For Reynold's model, we have shrinking stream lines and increasing three-dimensional graphs. $\gamma$ and Pr are reduced for both models.

\section{Introduction}

Non-Newtonian fluids have been a subject of great interest to researchers recently because of their various applications in industry and engineering. This is due to distinctive characteristics of such fluids in nature. In general, the mathematical problems in non-Newtonian fluids are more complicated because they are nonlinear and higher order than those in viscous fluids. Despite their complexities, scientists and engineers are engaged in non-Newtonian fluid dynamics. The analysis of boundary layer flow of viscous and non-Newtonian fluids has been the locus of extensive research by various scientists due to its importance in continuous casting, glass blowing, paper production, polymer extrusion, aerodynamic extrusion of plastic sheet, and several others. Rajagopal et al. [1] have focused their research towards nonNewtonian fluid flows due to stretching of a flat surface. As far as literature survey is concerned many researchers [2-23] have worked on MHD radiation effects of viscous fluids.
Effects of thermal diffusion and chemical reaction on MHD flow of a dusty viscoelastic fluid have been inspected by Prakash et al. [34]. Abdul Hakeem et al. [24] have found the effect of heat radiation in Walters' $\mathrm{B}$ fluid over a stretching sheet with nonuniform heat source/sink and elastic deformation. Recently, unsteady free convection flow in Walters' B fluid and heat transfer analysis have been presented by Khan et al. [24]. Wang and Ng [25] investigated a similar flow to the present study but for an electrically nonconducting fluid and outside a magnetic field.

Uddin et al. [26] studied MHD flow bounded by a nonlinearly stretching surface with radiation. Brownian motion and thermophoresis in magnetohydrodynamic (MHD) bioconvection flow of nanoliquid via nonlinear thermal radiation is addressed by Makinde and Animasaun [27]. The hydromagnetic pivot flows of an Oldroyd-B fluid in a porous medium was discussed by Khan et al. [28]. Khan et al. [29] studied the heat and mass transfer of viscoelastic MHD flow over a porous magnifying sheet with 
degeneration of energy and stress work. The flows of Walters' B fluid for numerical or applicable results for both steady and transitory at great length in a distinct range of geometries using broad scale of analytical or computational approaches have been studied [30-32]. Prakash et al. [33] inspected the effects of chemical reaction and thermal diffusion on the MHD flow of a dusty viscoelastic fluid. The effect of heat radiation in Walters' B fluid over a magnifying sheet with nonuniform elastic deformation and heat source was found by Abdul Hakeem et al. [34]. Khan et al. [24] represented the unsteady free convection flow in heat transfer analysis and Walters' B fluid. Under different pressure gradients the thermal effects of a dusty viscoelastic fluid on unsteady fluid between two parallel plates was studied by Madhurai and Kalpana [35]. The objective here is to study numerically the combined effects of the radiation and MHD on the flow of a viscoelastic fluid model past a porous plate with temperature dependent variable viscosity. The problem is divided into two different parts in which the first part explicates that the plate has greater temperature than fluids temperature. The second part describes that plate is insulated. To understand the phenomenon, Reynold's model and Vogel's model of variable viscosity with magnetohydrodynamic and radiation effects of viscoelastic Walters' B non-Newtonian fluid flow are incorporated. The shooting technique is habituated to attain the numerical solution of arising governing equations and solved with BVP4 software of Maple program. Three-dimensional and stream lines graphs were enlarged and reduced, respectively. The behavior of emerging parameters on the velocity and temperature profiles is studied with the help of graphs.

\section{Mathematical Equations}

The Cauchy stress tensor for Walters' B fluid is given by

$$
S=-p I+2 \eta_{0} \mathbf{e}-2 k_{0} \frac{\delta \mathbf{e}}{\delta t}
$$

where pressure of the fluid is pand

$$
\begin{aligned}
& \eta_{0}=\int_{0}^{\infty} N(\tau) \mathrm{d} \tau, \\
& k_{0}=\int_{0}^{\infty} \tau N(\tau) \mathrm{d} \tau .
\end{aligned}
$$

Here, $N(\tau)$ is distribution function with relaxation time $\tau$.

\section{Physical Modeling of the Problem}

The current problem gives the flow of a Walters' B fluid flow past an infinite spongy plate.

The temperature and velocity fields are

$$
\begin{aligned}
& \theta=\theta(y) \\
& \mathbf{v}=v(y) i+w(y) k .
\end{aligned}
$$

The governing equations are

$$
\begin{aligned}
\frac{\partial \rho}{\partial t}+\operatorname{div}(\rho \mathbf{v}) & =0, \\
\rho \frac{\mathrm{d} \mathbf{v}}{\mathrm{d} t} & =\operatorname{div}(S)+\rho \mathbf{b}, \\
\rho \frac{\mathrm{d} \mathbf{e}}{\mathrm{d} t} & =S \cdot L-\operatorname{div}(\mathbf{q})+\rho \mathbf{r} .
\end{aligned}
$$

For an incompressible fluid, (4) takes the form

$$
\begin{aligned}
\operatorname{div} \mathbf{v} & =0, \\
u & =-v_{0}=\text { Constant, }
\end{aligned}
$$

where $v_{0}>0$ is suction and $v_{0}<0$ represents blowing at the plate. Momentum equation under the effects of magnetohydrodynamics for the current problem is

$$
\begin{aligned}
& \frac{\partial P}{\partial z}=\rho v_{0} \frac{\mathrm{d} w}{\mathrm{~d} x}+\frac{\mathrm{d} \eta_{0}}{\mathrm{~d} y} \frac{\mathrm{d} w}{\mathrm{~d} y}+\eta_{0} \frac{\mathrm{d}^{2} w}{\mathrm{~d} y^{2}}+k_{0} v_{0} \frac{\mathrm{d}^{3} w}{\mathrm{~d} y^{3}}-\sigma B_{0}^{2} w \\
& \frac{\partial P}{\partial y}=2 k_{0} \frac{\mathrm{d}}{\mathrm{d} y}\left[\left(\frac{\mathrm{d} w}{\mathrm{~d} y}\right)^{2}\right], \\
& \frac{\partial P}{\partial x}=0 .
\end{aligned}
$$

Define pressure as modified as

$$
\widehat{P}=P-\left(2 k_{0}\right)\left(\frac{\mathrm{d} w}{\mathrm{~d} y}\right)^{2}
$$

Equations (8)-(10) with magnetohydrodynamic effects formed as

$$
\begin{aligned}
& \frac{\partial \widehat{P}}{\partial z}=\rho v_{0} \frac{\mathrm{d} w}{\mathrm{~d} y}+\frac{\mathrm{d} \mu_{0}}{\mathrm{~d} y} \frac{\mathrm{d} w}{\mathrm{~d} y}+\eta_{0} \frac{\mathrm{d}^{2} w}{\mathrm{~d} y^{2}}+k_{0} v_{0} \frac{\mathrm{d}^{3} w}{\mathrm{~d} y^{3}}-\sigma B_{0}^{2} w \\
& \frac{\partial \widehat{P}}{\partial y}=0 \\
& \frac{\partial \widehat{P}}{\partial x}=0 .
\end{aligned}
$$

Equation (12) can be written as

$$
\rho v_{0} \frac{\mathrm{d} w}{\mathrm{~d} y}+\frac{\mathrm{d} \mu_{0}}{\mathrm{~d} y} \frac{\mathrm{d} w}{\mathrm{~d} y}+\eta_{0} \frac{\mathrm{d}^{2} w}{\mathrm{~d} y^{2}}+k_{0} v_{0} \frac{\mathrm{d}^{3} w}{\mathrm{~d} y^{3}}-\sigma B_{0}^{2} w=L_{1},
$$

where

$$
\frac{\partial \widehat{P}}{\partial z}=L_{1}
$$

The boundary conditions are

$$
\begin{aligned}
w(0)= & 0, \\
& w(y) \longrightarrow W_{\infty}, \quad \text { as } y \longrightarrow \infty .
\end{aligned}
$$

As we have $3^{\text {rd }}$-order equation (15), so we need another boundary condition. Therefore, in free stream, 


$$
\left.S_{y z}\right|_{y \rightarrow \infty}=\left[\eta_{0} \frac{\mathrm{d}^{2} w}{\mathrm{~d} y^{2}}+k_{0} v_{0} \frac{\mathrm{d}^{3} w}{\mathrm{~d} y^{3}}\right]_{y \rightarrow \infty}=0 .
$$

We use the following conditions:

$$
\frac{\mathrm{d} w}{\mathrm{~d} y}=0, \quad \text { as } y \longrightarrow \infty,
$$

and also take another assumption that

$$
L_{1}=0 \text {. }
$$

Now, we are going to discuss the heat transfer in (6).

$$
q=-k \operatorname{grad} \theta,
$$

where $\mathbf{q}$ is heat flux. The radiation parameter is

$$
q_{r}=-\frac{4 \sigma^{*}}{3 K^{*}} \frac{\partial \theta^{4}}{\partial x}
$$

Then

$$
k \frac{\mathrm{d}^{2} \theta}{\mathrm{d} y^{2}}+\rho C_{p} v_{0} \frac{\mathrm{d} \theta}{\mathrm{d} y}+\eta_{0}\left(\frac{\mathrm{d} w}{\mathrm{~d} y}\right)+k_{0} v_{0}\left(\frac{\mathrm{d} w}{\mathrm{~d} y}\right) \frac{\mathrm{d}^{2} w}{\mathrm{~d} y^{2}}-\frac{1}{\rho C_{p}} \frac{\partial q_{r}}{\partial y}=0 .
$$

$C_{p}$ is specific heat and the boundary conditions for (21) are given in two parts as follows:

Part 1:

This part gives conditions for constant wall temperature of the fluid:

$$
\begin{array}{r}
\theta(0)=\theta_{0}, \\
\theta(x) \longrightarrow 0_{\infty}, \quad \text { as } x \longrightarrow \infty .
\end{array}
$$

Case 2:

This gives insulated wall of the fluid

$$
\begin{aligned}
& \left.\frac{\mathrm{d} \theta}{\mathrm{d} y}\right|_{y \rightarrow 0}= \\
& \quad \theta(y) \longrightarrow \theta_{\infty}, \quad \text { as } y \longrightarrow \infty .
\end{aligned}
$$

3.1. Solution for Constant Wall Temperature. The dimensionless parameters can be defined as

$$
\begin{aligned}
& \bar{Y}=\frac{Y}{L}, \\
& \bar{w}=\frac{w}{W_{\infty}}, \\
& \bar{\theta}=\frac{\theta-\theta_{\infty}}{\theta_{0}-\theta_{\infty}},
\end{aligned}
$$

where

$$
L=\frac{k_{0} v_{0}}{\eta_{0}^{*}}
$$

is the characteristic "length" and also

$$
\overline{\eta_{0}}=\frac{\eta_{0}}{\eta_{0}^{*}}
$$

Using the above relations, (15) and (23) become

$$
\begin{array}{r}
\frac{\mathrm{d}^{3} \bar{w}}{\mathrm{~d} \bar{y}^{3}}+\eta_{0} \frac{\mathrm{d}^{2} \bar{w}}{\mathrm{~d} \bar{y}^{2}}+\gamma \frac{\mathrm{d} \bar{w}}{\mathrm{~d} \bar{y}}+\frac{\mathrm{d} \eta_{0}}{\mathrm{~d} \bar{y}} \frac{\mathrm{d} \bar{w}}{\mathrm{~d} \bar{y}}-\gamma M \bar{w}=L_{2}, \\
\left(1+\frac{4}{3} R\right) \frac{\mathrm{d}^{2} \bar{\theta}}{\mathrm{d} \bar{y}^{2}}+\gamma \operatorname{Pr} \frac{\mathrm{d} \bar{\theta}}{\mathrm{d} \bar{y}}+\lambda \eta_{0}\left(\frac{\mathrm{d} \bar{w}}{\mathrm{~d} \bar{y}}\right)^{2}+\lambda\left(\frac{\mathrm{d} \bar{w}}{\mathrm{~d} \bar{y}}\right) \frac{\mathrm{d}^{2} \bar{w}}{\mathrm{~d} \bar{y}^{2}}=0 .
\end{array}
$$

For simplicity, the bars are removed from (29)-(30) and get

$$
\begin{array}{r}
\frac{\mathrm{d}^{3} w}{\mathrm{~d} y^{3}}+\eta_{0} \frac{\mathrm{d}^{2} w}{\mathrm{~d} y^{2}}+\gamma \frac{\mathrm{d} w}{\mathrm{~d} y}+\frac{\mathrm{d} \eta_{0}}{\mathrm{~d} y} \frac{\mathrm{d} w}{\mathrm{~d} y}-\gamma M w=L_{2}, \\
\left(1+\frac{4}{3} R\right) \frac{\mathrm{d}^{2} \theta}{\mathrm{d} y^{2}}+\gamma \operatorname{Pr} \frac{\mathrm{d} \theta}{\mathrm{d} y}+\lambda \eta_{0}\left(\frac{\mathrm{d} w}{\mathrm{~d} y}\right)^{2}+\lambda\left(\frac{\mathrm{d} w}{\mathrm{~d} y}\right) \frac{\mathrm{d}^{2} w}{\mathrm{~d} y^{2}}=0,
\end{array}
$$


where

$$
\begin{aligned}
\gamma & =\frac{\rho k_{0} W_{\infty}^{2}}{\eta_{0}^{* 2}}, \\
M & =\frac{\sigma B_{0}^{2} K_{0}}{\rho \eta_{0}^{2}}, \\
R & =\frac{4 \sigma^{*} \theta_{\infty}^{3}}{K K^{*}}, \\
\operatorname{Pr} & =\frac{\eta_{0}^{*} C}{k}, \\
\lambda & =\frac{W_{\infty}^{2} \eta_{0}}{k\left(\theta_{0}-\theta_{\infty}\right)} .
\end{aligned}
$$

Here, $\gamma$ is dimensionless length, $M$ is MHD term coefficient, $R$ is radiation, $\operatorname{Pr}$ is Prandtl number and $\lambda$ is dimensionless quantity. The dimensionless boundary conditions are

$$
\begin{aligned}
& \begin{array}{c}
w(0)= \\
w
\end{array} 01 \text { as } y \longrightarrow \infty, \\
& \frac{\mathrm{d} w}{\mathrm{~d} y} \longrightarrow 0 \text { as } y \longrightarrow \infty, \\
& \theta(0)= 1, \\
& \theta \longrightarrow 1 \text { as } y \longrightarrow \infty .
\end{aligned}
$$

3.2. Solution for Insulated Plate. Here, we introduce nondimensional temperature parameter

$$
\theta^{*}=\frac{\theta-\theta_{\infty}}{\theta_{b}-\theta_{\infty}},
$$

where $\theta_{b}$ is bulk temperature. Eckert number is

$$
E^{*}=\frac{W_{\infty}^{2}}{c\left(\theta_{b}-\theta_{\infty}\right)} .
$$

The boundary conditions for dimensionless flow are

$$
\begin{array}{r}
\left.\frac{\mathrm{d} \theta}{\mathrm{d} y}\right|_{y \longrightarrow 0}=0, \\
\theta(y) \longrightarrow \theta_{\infty} \text { as } y \longrightarrow \infty .
\end{array}
$$

The skin friction and Nusselt number [7] are expressed as

$$
\begin{aligned}
C_{f} & =\frac{\tau_{w}}{(1 / 2) \rho W^{2}}, \\
\mathrm{Nu} & =\frac{y q_{w}}{k\left(T_{w}-T_{\infty}\right)},
\end{aligned}
$$

where

$$
\mathrm{Nu}=-\theta^{\prime}(0)
$$

$\mathrm{C}_{f}$ is skin friction coefficient and $\mathrm{Nu}$ is Nusselt number. Also,

$$
\begin{aligned}
& \tau_{w}=\left[\eta_{0} \frac{\mathrm{d} w}{\mathrm{~d} y}+k_{0} v_{0} \frac{\mathrm{d}^{2} w}{\mathrm{~d} y^{2}}\right]_{y \longrightarrow 0}, \\
& q_{w}=-k\left(\frac{\partial \theta}{\partial y}\right)_{y \longrightarrow 0},
\end{aligned}
$$

and by using similarity transformation, we get

$$
\begin{aligned}
\frac{1}{2} C_{f} \operatorname{Re} & =(1-N \theta) w^{\prime}(0)+w^{\prime \prime}(0), \\
\mathrm{Nu} & =-\theta^{\prime}(0) .
\end{aligned}
$$

Here, Re represents Reynold number.

\section{Reynold's Model}

The viscosity for this model is expressed as

$$
\eta_{0}=e^{-N \theta}
$$

which can be solved by using Maclaurin's series as

$$
\eta_{0}=1-N \theta \text {. }
$$

Using the value of $\eta_{0}$ in (31) and (32), we obtain

$$
\begin{array}{r}
\frac{\mathrm{d}^{3} w}{\mathrm{~d} y^{3}}+\frac{\mathrm{d}^{2} w}{\mathrm{~d} y^{2}}-N \theta \frac{\mathrm{d}^{2} w}{\mathrm{~d} y^{2}}+\gamma \frac{\mathrm{d} w}{\mathrm{~d} y}-N \frac{\mathrm{d} \theta}{\mathrm{d} y} \frac{\mathrm{d} w}{\mathrm{~d} y}-\gamma M w=L_{2}, \\
\left(1+\frac{4}{3} R\right) \frac{\mathrm{d}^{2} \theta}{\mathrm{d} y^{2}}+\gamma \operatorname{Pr} \frac{\mathrm{d} \theta}{\mathrm{d} y}+\lambda\left(\frac{\mathrm{d} w}{\mathrm{~d} y}\right)^{2}-\lambda N \theta\left(\frac{\mathrm{d} w}{\mathrm{~d} y}\right)^{2}+\lambda\left(\frac{\mathrm{d} w}{\mathrm{~d} y}\right) \frac{\mathrm{d}^{2} w}{\mathrm{~d} y^{2}}-\frac{1}{\rho C_{p}} \frac{\partial q_{r}}{\partial y}=0 .
\end{array}
$$




\section{Vogel's Model}

In this case,

$$
\mu_{0}=\eta_{0}^{*} \exp \left(\frac{D}{(E+\theta)}-\theta_{w}\right),
$$

The above equation can be written in the form

$$
\eta_{0}=-\frac{G}{G^{*}}\left(1-\frac{D \theta}{E^{2}}\right) .
$$

Using (47) in (31) and (32), we get

which implies the following.

$$
\begin{array}{r}
\frac{\mathrm{d}^{3} w}{\mathrm{~d} y^{3}}+\frac{G}{G^{*}} \frac{\mathrm{d}^{2} w}{\mathrm{~d} y^{2}}-\frac{D G}{G^{*} E^{2}} \frac{\mathrm{d}^{2} w}{\mathrm{~d} y^{2}}+\gamma \frac{\mathrm{d} w}{\mathrm{~d} y}-\frac{D G}{G^{*} E^{2}} \frac{\mathrm{d} \theta}{\mathrm{d} y} \frac{\mathrm{d} w}{\mathrm{~d} y}-\gamma M w=L_{2}, \\
\left(1+\frac{4}{3} R\right) \frac{\mathrm{d}^{2} \theta}{\mathrm{d} y^{2}}+\gamma \operatorname{Pr} \frac{\mathrm{d} \theta}{\mathrm{d} y}+\lambda \frac{G}{G^{*}}\left(\frac{\mathrm{d} w}{\mathrm{~d} y}\right)^{2}-\lambda \frac{D G}{G^{*} E^{2}} \theta\left(\frac{\mathrm{d} w}{\mathrm{~d} y}\right)^{2}+\lambda\left(\frac{\mathrm{d} w}{\mathrm{~d} y}\right) \frac{\mathrm{d}^{2} w}{\mathrm{~d} y^{2}}-\frac{1}{\rho C_{p}} \frac{\partial q_{r}}{\partial y}=0 .
\end{array}
$$

\section{Numerical Solution}

For the purpose of numerical investigation, we have made comparison of our current article with three previous publications, which shows our results in this study are better than the previous literature $[4,12,20]$. The solution for (44) and (45) and (48) and (49) is obtained by using shooting technique with Runge-Kutta method [23, 36-38].

6.1. Solution for Reynold's Model. Equations (44) and (45) are for the desired form

$$
\begin{aligned}
& w^{\prime \prime \prime}=-\gamma w^{\prime}-(1-N \theta) w^{\prime \prime}+N \theta^{\prime} w^{\prime}-\gamma M w \\
& \theta^{\prime \prime}=-\frac{1}{(1+(4 / 3) R)}\left(\gamma \operatorname{Pr} \theta^{\prime}-\lambda\left(w^{\prime}\right)^{2}-\lambda w^{\prime} w^{\prime \prime}+N \theta\left(w^{\prime}\right)^{2}-\frac{1}{\rho C_{p}} \frac{\partial q_{r}}{\partial y}\right) .
\end{aligned}
$$

Now, we define new variables,

By using new variables, we get

$$
\begin{aligned}
w & =s_{1}, \\
w^{\prime} & =s_{2}, \\
w^{\prime \prime} & =s_{3}, \\
w^{\prime \prime \prime} & =s_{3}^{\prime}, \\
\theta & =s_{4}, \\
\theta^{\prime} & =s_{5}, \\
\theta^{\prime \prime} & =s_{5}^{\prime} .
\end{aligned}
$$

$$
\begin{aligned}
& s_{1}^{\prime}=s_{2}, s_{2}^{\prime}=s_{3}, s_{4}^{\prime}=s_{5}, \\
& s_{3}^{\prime}=-\gamma w^{\prime}-(1-N \theta) w^{\prime \prime}+N \theta^{\prime} w^{\prime}-\gamma M w, \\
& s_{5}^{\prime}=-\frac{1}{(1+(4 / 3) R)}\left(\gamma \operatorname{Pr} \theta^{\prime}-\lambda\left(w^{\prime}\right)^{2}-\lambda w^{\prime} w^{\prime \prime}+N \theta\left(w^{\prime}\right)^{2}-\frac{1}{\rho C_{p}} \frac{\partial q_{r}}{\partial y}\right) .
\end{aligned}
$$




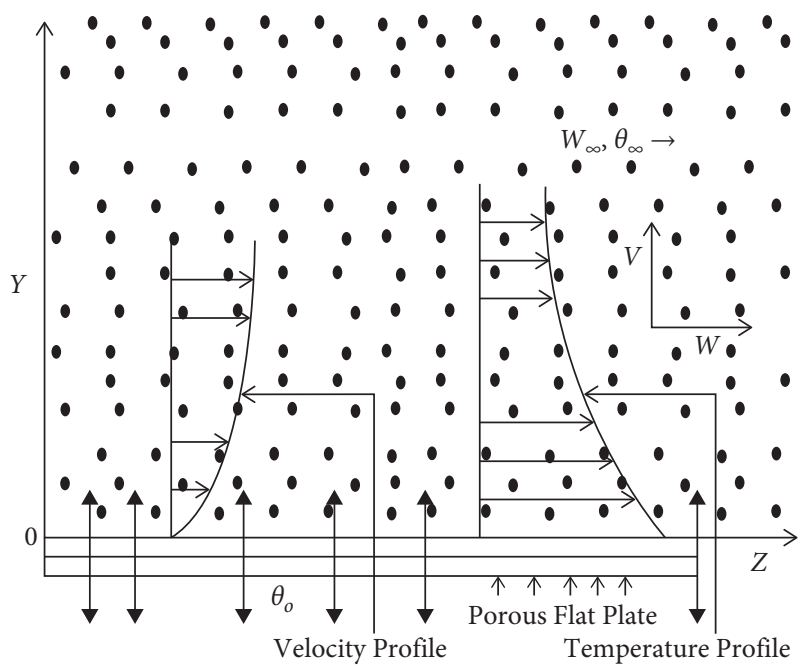

FIgURE 1: Physical geometry of the problem.

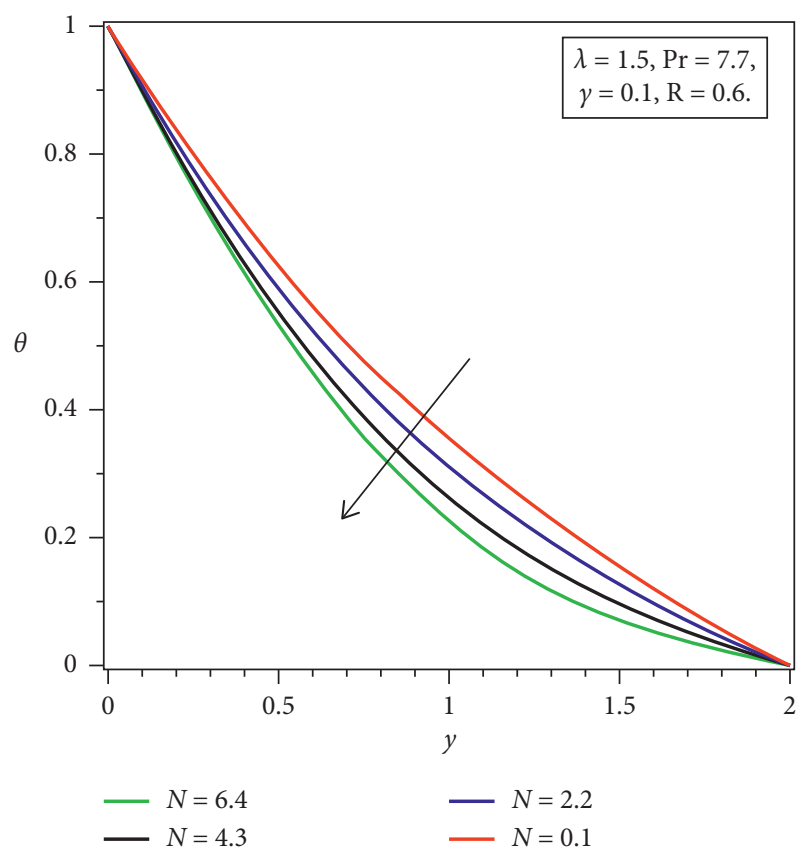

FIGURE 2: Effects of $N$ on temperature portray for Reynold's model.

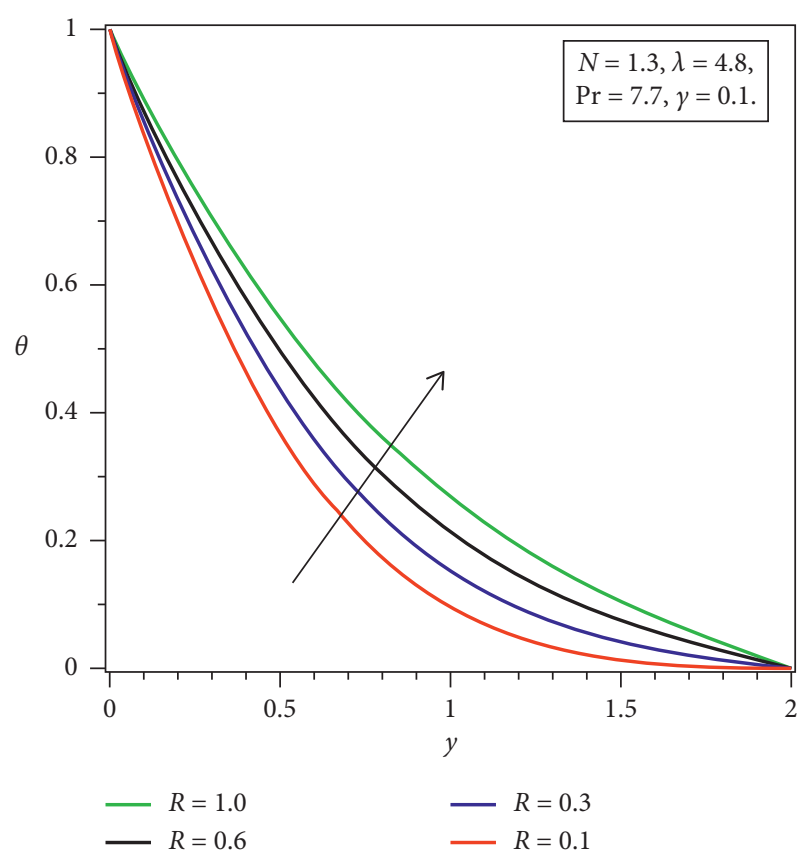

Figure 3: Influences of $R$ on temperature outline for Reynold's model.

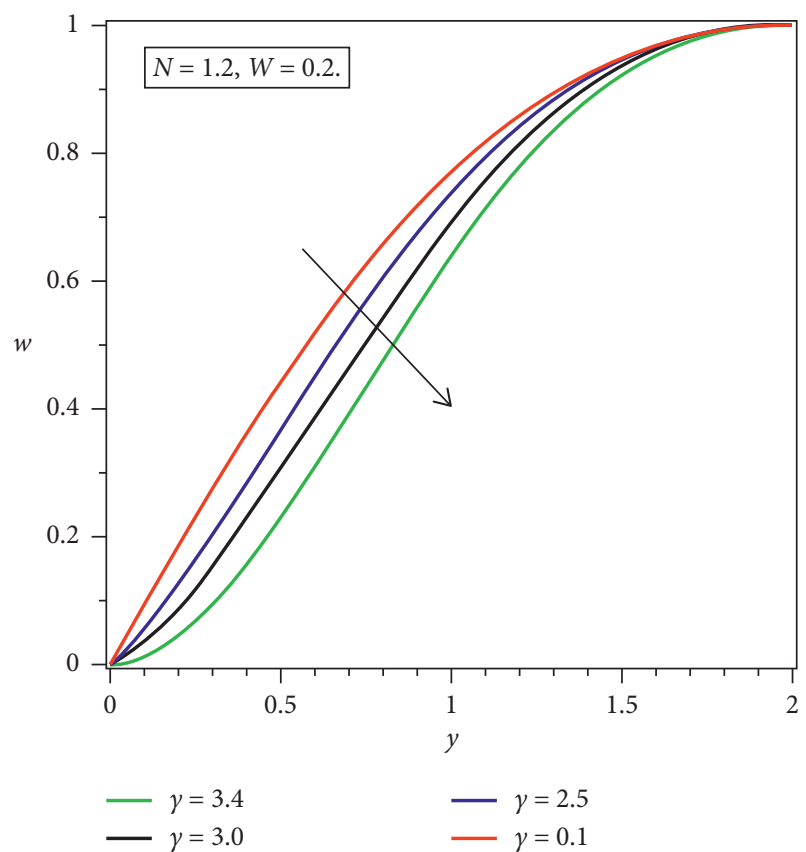

Figure 4: Impact of on velocity field for Reynold's model. 


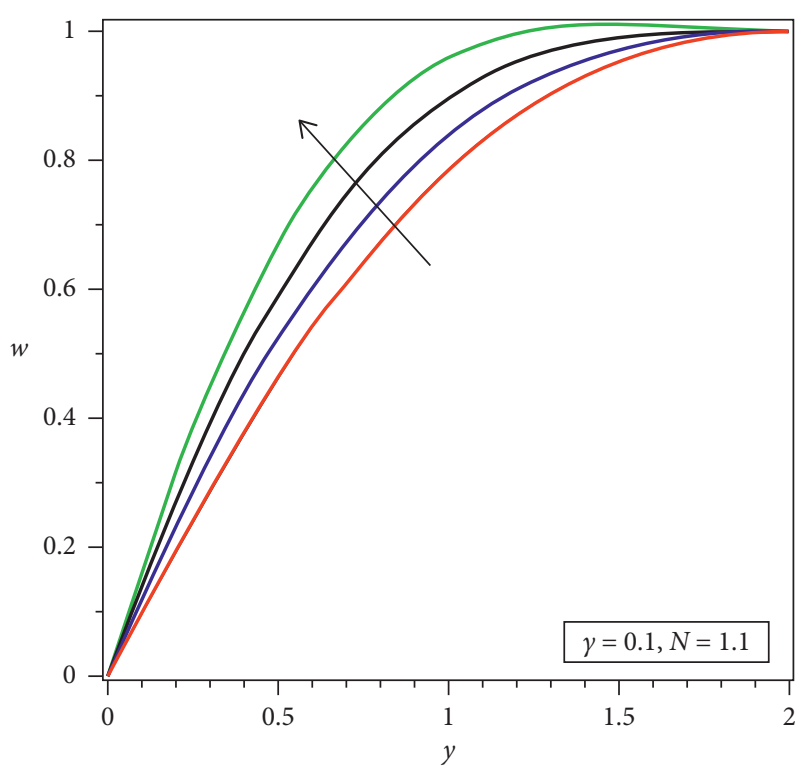

$$
\begin{aligned}
W=9.4 & -W=3.2 \\
W=6.3 & -W=0.2
\end{aligned}
$$

FIgURE 5: Effects of $W$ on velocity profile for Reynold's model.

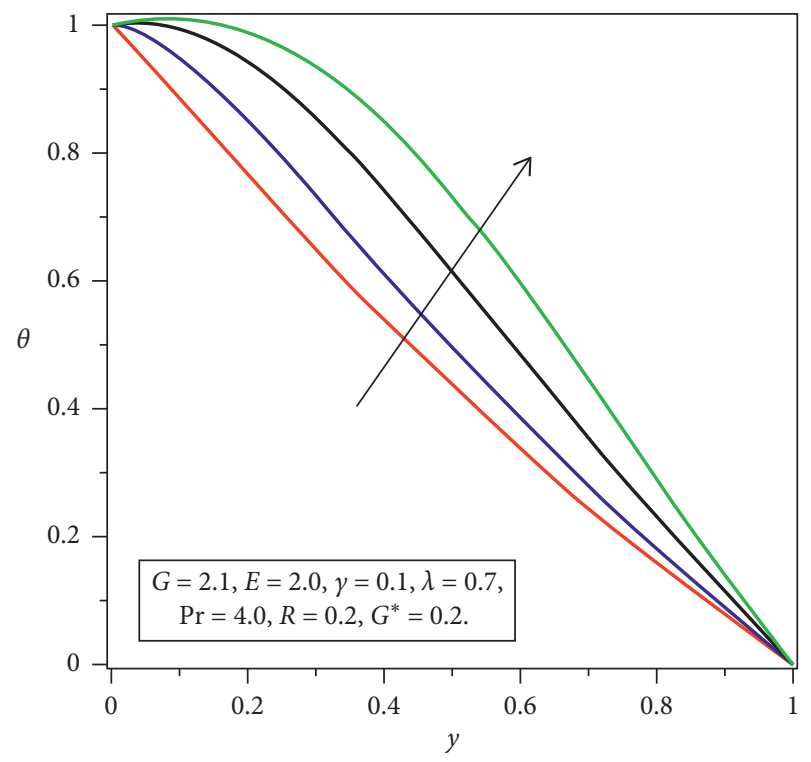

$$
\begin{aligned}
& \text { - } D=0.3 \\
& \text { — } D=1.5 \\
& \text { - D }=2.5
\end{aligned}
$$

FIGURE 6: Impact of $D$ on temperature outline for Vogel's model.

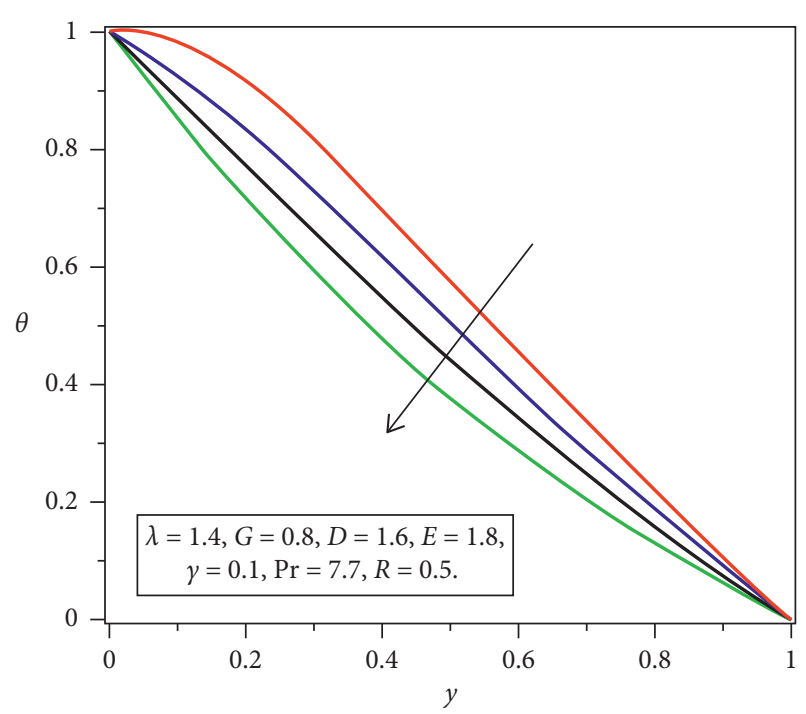

$$
\begin{aligned}
-G^{*} & =0.4 & -G^{*} & =0.17 \\
-G^{*} & =0.25 & -G^{*} & =0.1
\end{aligned}
$$

Figure 7: Effect of $G^{*}$ on temperature field for Vogel's model.

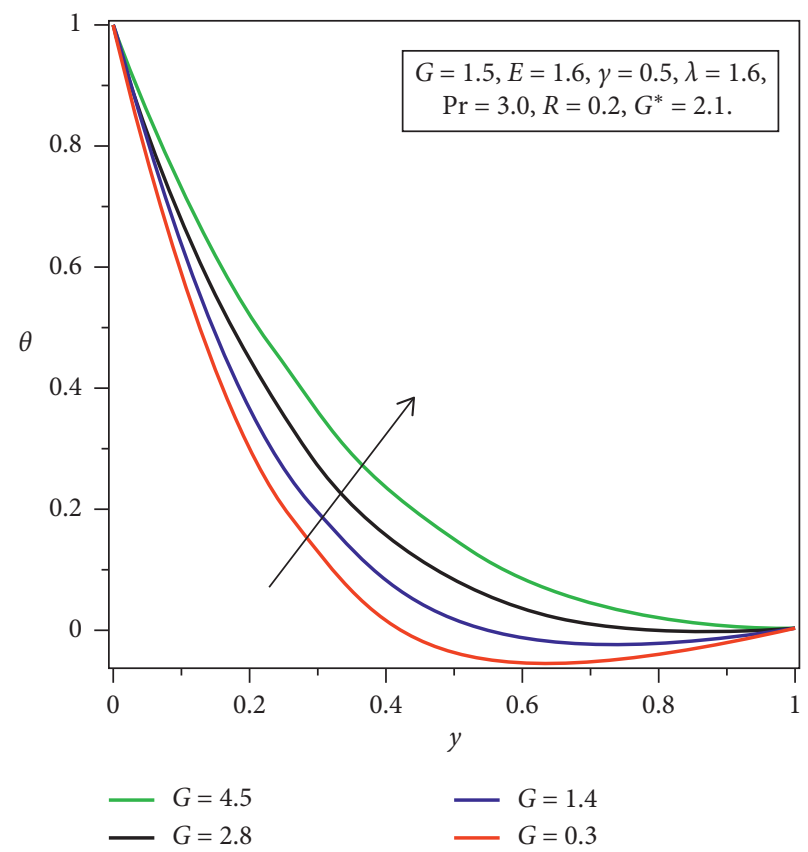

FIGURE 8: Impact of $G$ on temperature profile for Vogel's model. 


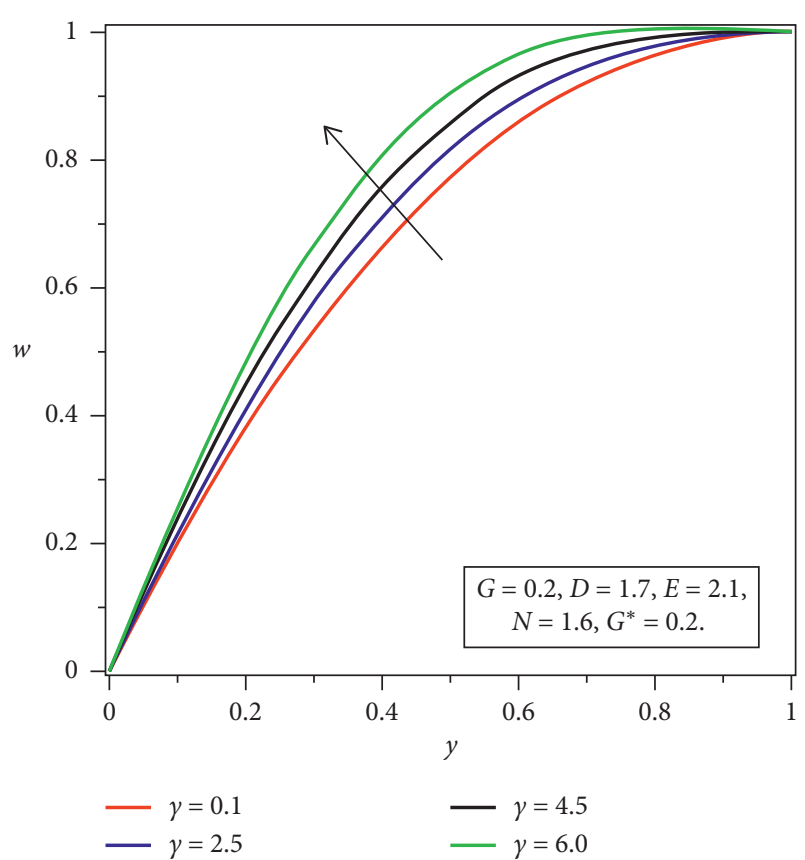

FIGURE 9: Influence of on velocity profile for Vogel's model.

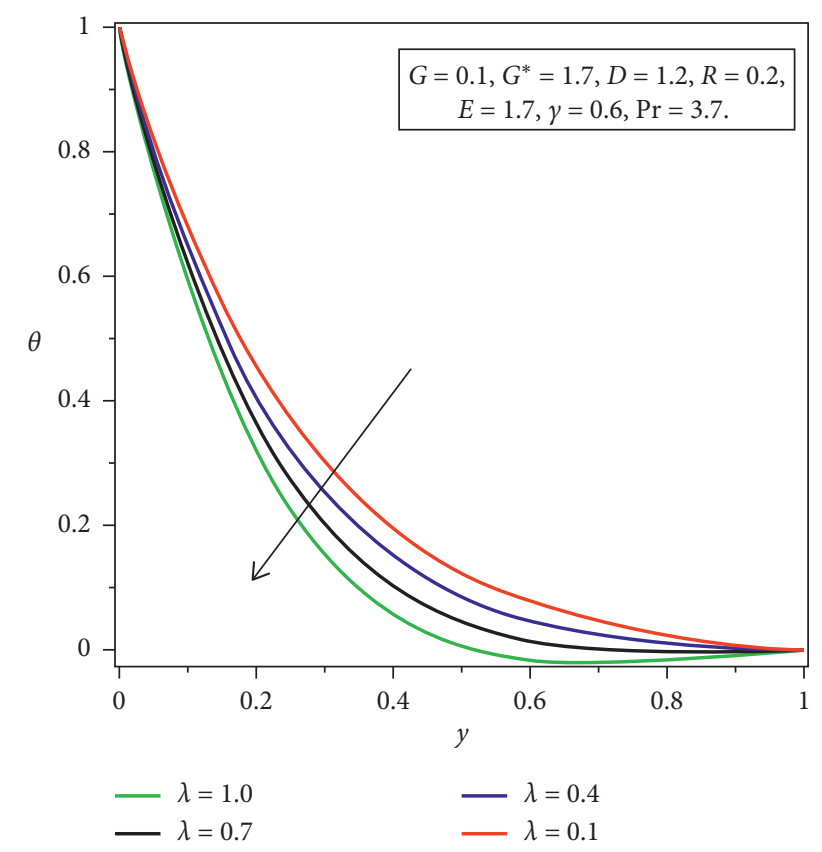

Figure 10: Effect of $\gamma$ on temperature outline for Vogel's model.

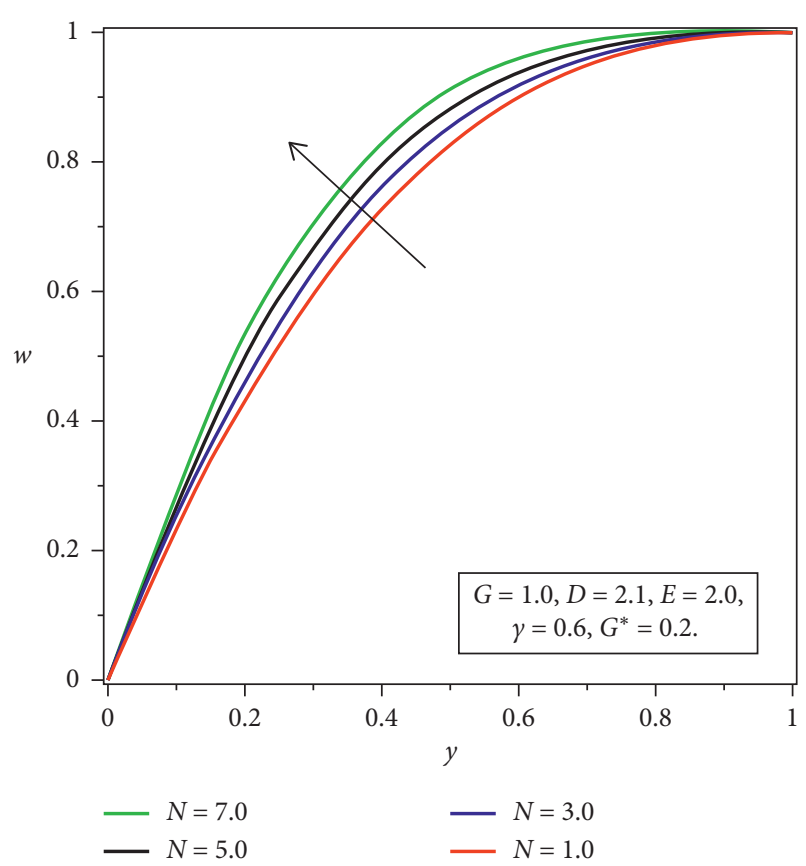

FIGURE 11: Influences of $N$ on velocity field for Vogel's model.

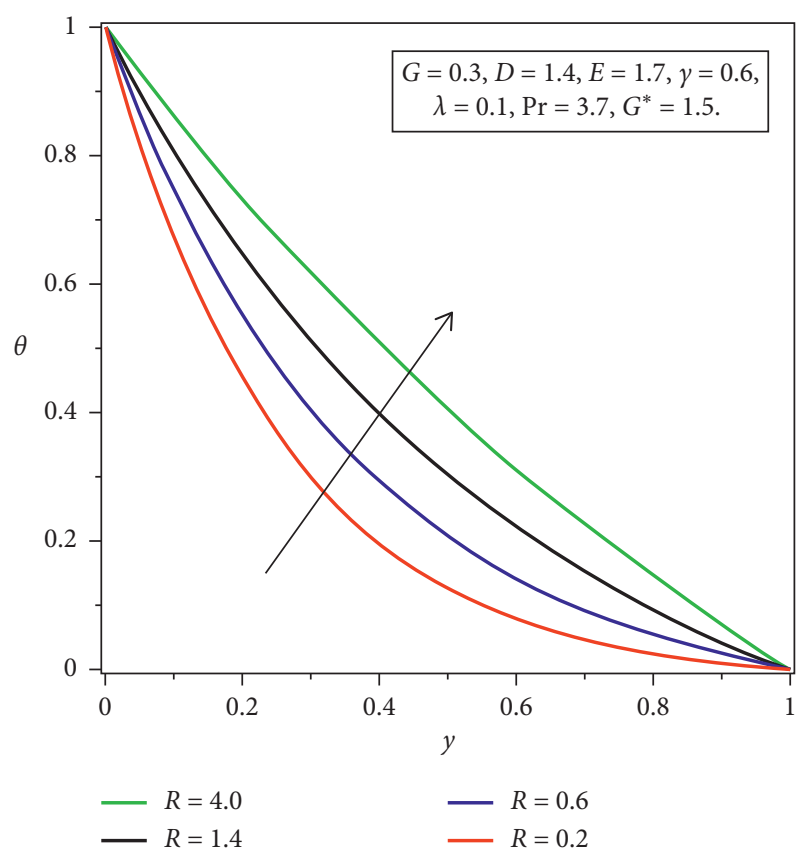

Figure 12: Impact of $R$ on temperature outline for Vogel's model. 


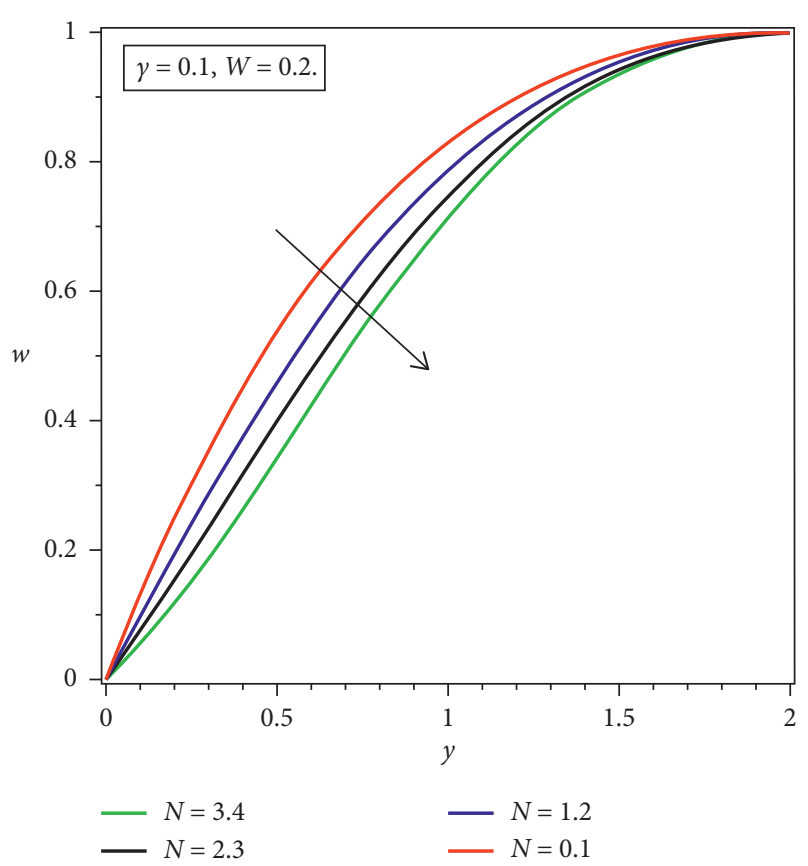

FIGURE 13: Effects of $N$ on velocity profile for Reynold's model.

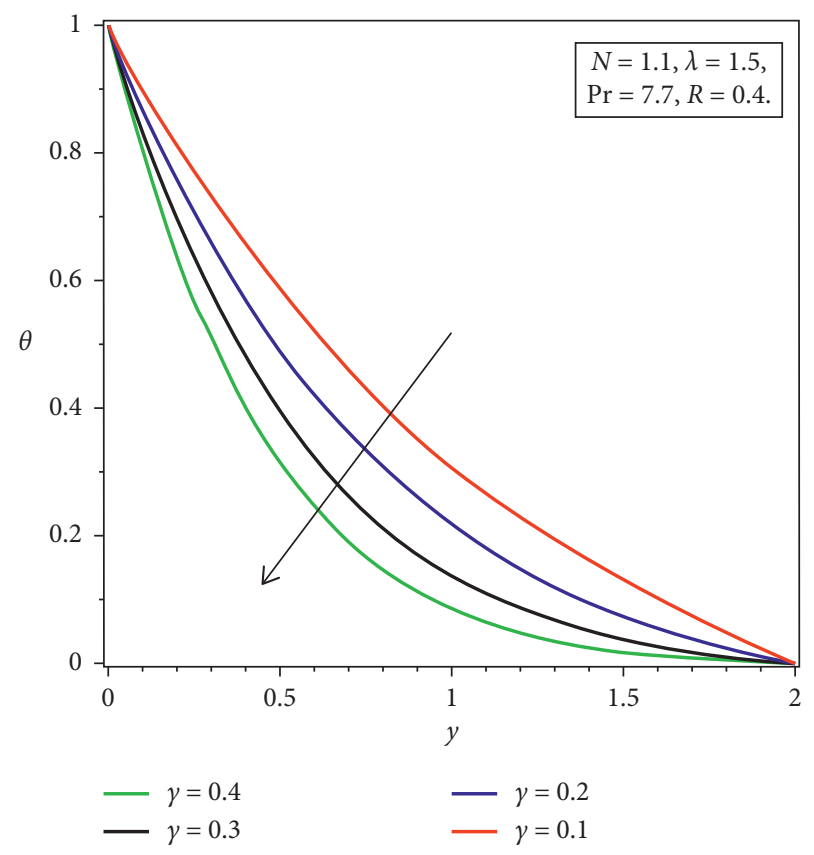

FIGURE 14: Impact of $\gamma$ on temperature field for Reynold's model.

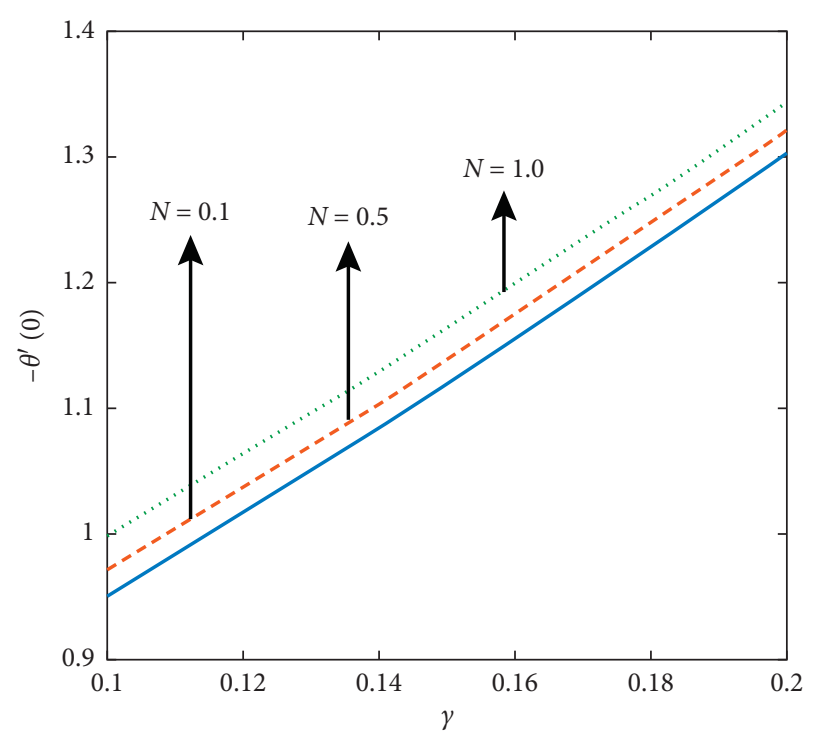

Figure 15: Effects of $\gamma$ and $N$ on Nusselt number for Reynold's model.

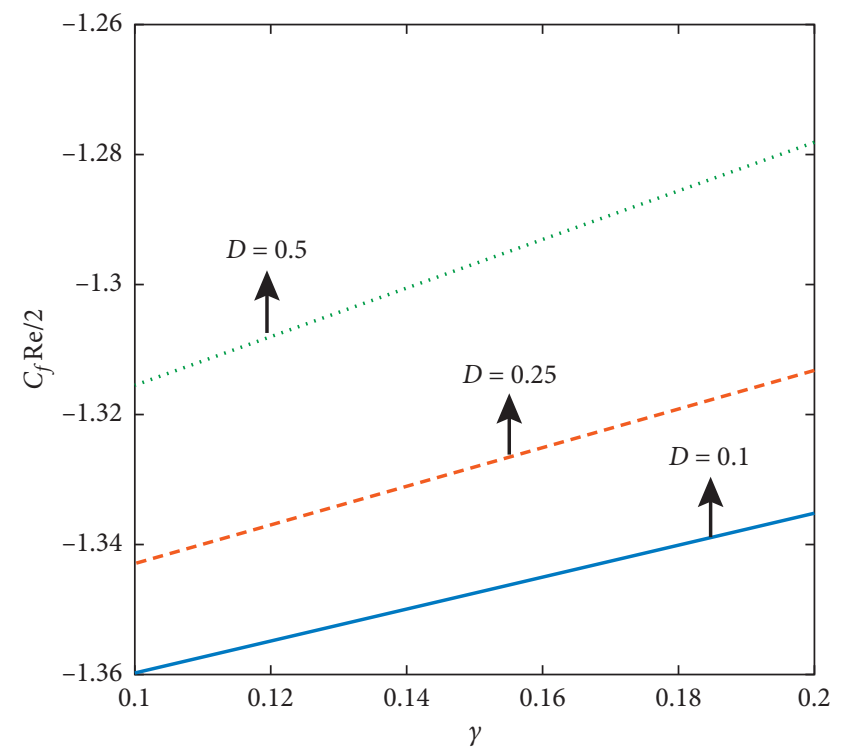

Figure 16: Effects of $\gamma$ and $D$ on skin friction for Vogel's model. 


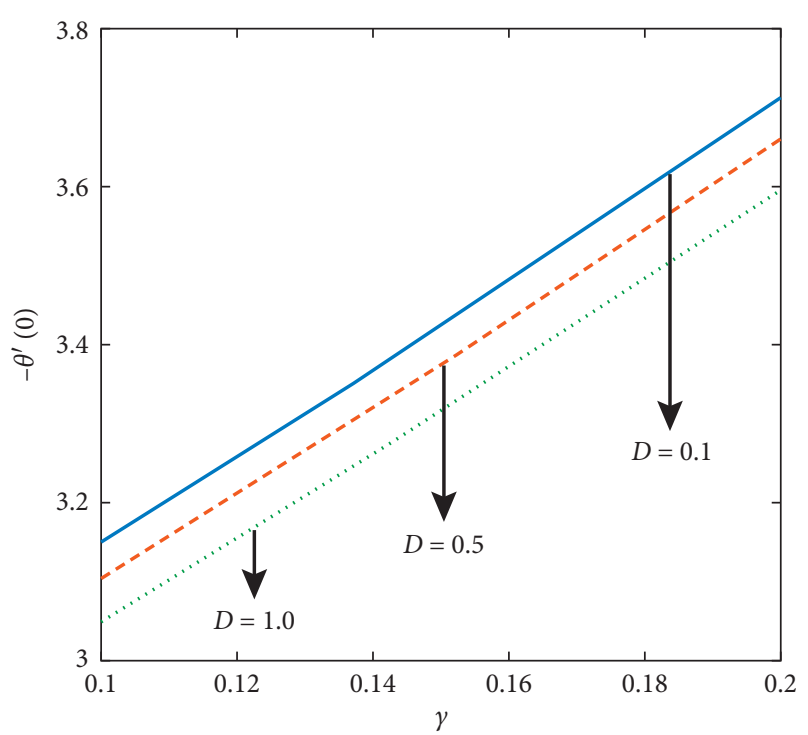

Figure 17: Effects of $\gamma$ and $D$ on Nusselt number for Vogel's model.

Along with boundary conditions,

$$
\begin{aligned}
s_{1}(0) & =0, \\
s_{1}(\infty) & =1, \\
s_{2}(0) & =1, \\
s_{2}(\infty) & =0, \\
s_{4}(0) & =1, \\
s_{4}(\infty) & =0 .
\end{aligned}
$$

$\gamma=0.1$

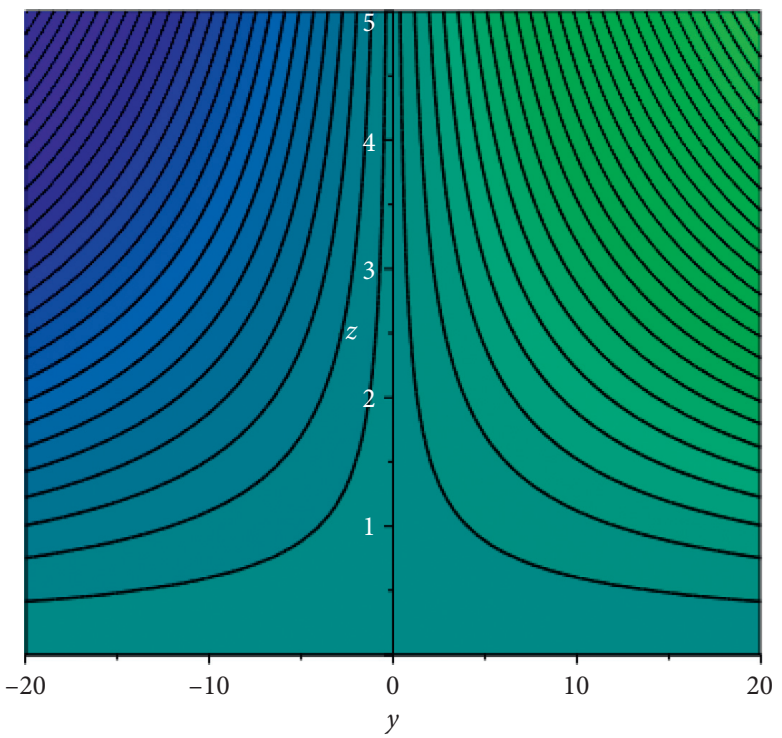

Figure 18: Stream lines for $\gamma=0.1$ for Reynold's model.

6.2. Solution for Vogel's Model. In this solution, (48) and (49) are

$$
\begin{aligned}
& w^{\prime \prime \prime}=-\gamma w^{\prime}-\left(1-\frac{D}{E^{2}}\right) \frac{G}{G^{*}} w^{\prime \prime}+\frac{D G}{G^{*} E^{2}} \theta^{\prime} w^{\prime}-\gamma M w, \\
& \theta^{\prime \prime}=-\frac{1}{(1+(4 / 3) R)}\left(-\gamma \operatorname{Pr} \theta^{\prime}-\left(1+\frac{D \theta}{E^{2}}\right) \frac{G}{G^{*}} \lambda\left(w^{\prime}\right)^{2}-\lambda w^{\prime} w^{\prime \prime}-\frac{1}{\rho C_{p}} \frac{\partial q_{r}}{\partial y}\right) .
\end{aligned}
$$

As previous case,

$$
\begin{aligned}
& s_{3}^{\prime}=-\gamma w^{\prime}-\left(1-\frac{D}{E^{2}}\right) \frac{G}{G^{*}} w^{\prime \prime}+\frac{D G}{G^{*} E^{2}} \theta^{\prime} w^{\prime \prime}-\gamma M w, \\
& s_{5}^{\prime}=-\frac{1}{(1+(4 / 3) R)}\left(-\gamma \operatorname{Pr} \theta^{\prime}-\left(1+\frac{D \theta}{E^{2}}\right) \frac{G}{G^{*}} \lambda\left(w^{\prime}\right)^{2}-\lambda w^{\prime} w^{\prime \prime}-\frac{1}{\rho C_{p}} \frac{\partial q_{r}}{\partial y}\right) .
\end{aligned}
$$

with the same boundary conditions as in (53).

\section{Graphical Results and Discussion}

In graphical portray, Figure 1 explains the physical geometry of the problem. Figure 2 gives portray of
$N=0.1,2.2,4.3,6.4$ for Reynold's model on temperature field. Figure 3 shows the behavior of $R=0.1,0.3,0.6,1.0$ for Reynold's model on temperature portray. Figure 4 renders effects of $\gamma=0.1,2.5,3.0,3.4$ for Reynold's model on velocity field. Figure 5 describes effects of $W=0.2,3.2,6.2,9.4$ on Reynold's model for velocity 


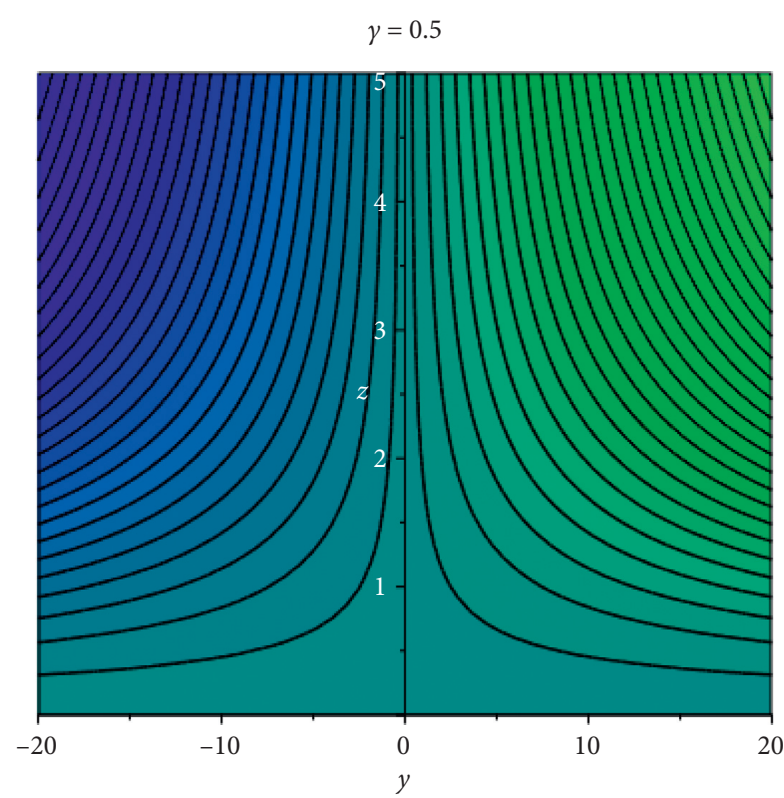

Figure 19: Stream lines for $\gamma=0.5$ for Reynold's model.

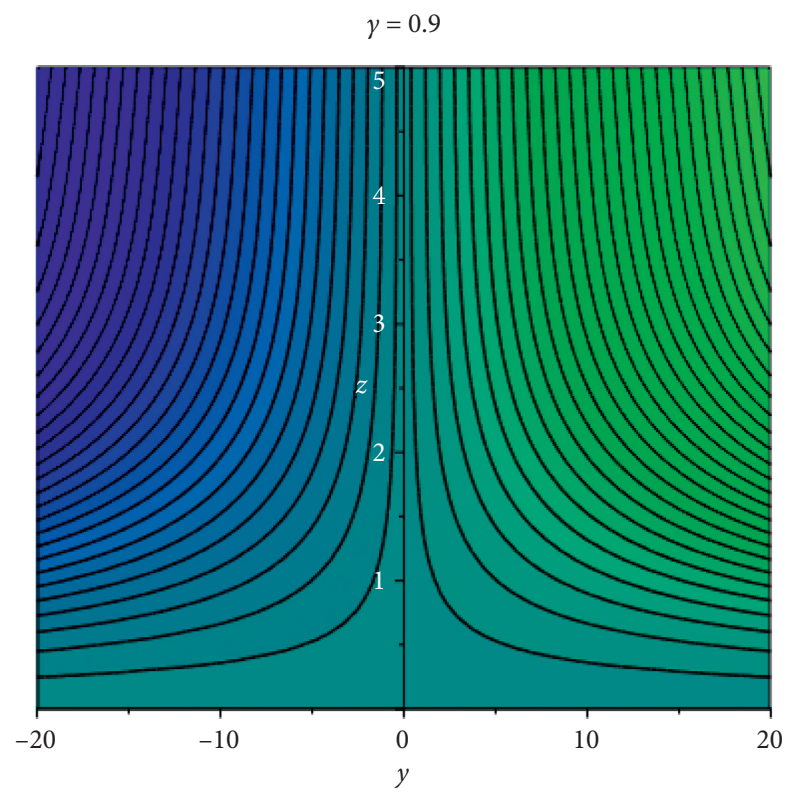

Figure 20: Stream lines for $\gamma=0.9$ for Reynold's model.

profile. Figure 6 draws the consequences of $D=0.3,1.5,2.5,3.0$ on temperature distribution for Reynold's model. Figure 7 limns the impact of $G^{*}=0.1,0.17,0.25,0.4$ on temperature profile for Vogel's model. Figure 8 tells the influence of $G=0.3,1.4,2.8,4.5$ for Vogel's model on temperature profile. Figure 9 represents $\gamma=0.1,2.5,4.5,6.0$ on Vogel's model for velocity outline. Figure 10 shows the effect of $\lambda=0.1,0.4,0.7,1.0$ on Vogel's model for temperature. Figure 11 depicts impact of $N=1.0,3.0,5.0,7.0$ on Vogel's model for velocity profile. Figure 12 shows the behavior of $R=0.2,0.6,1.4,4.0$ on Vogel's model for temperature portray. Figure 13 gives the effects of $N=0.1,1.2,2.3,3.4$ on velocity profile for

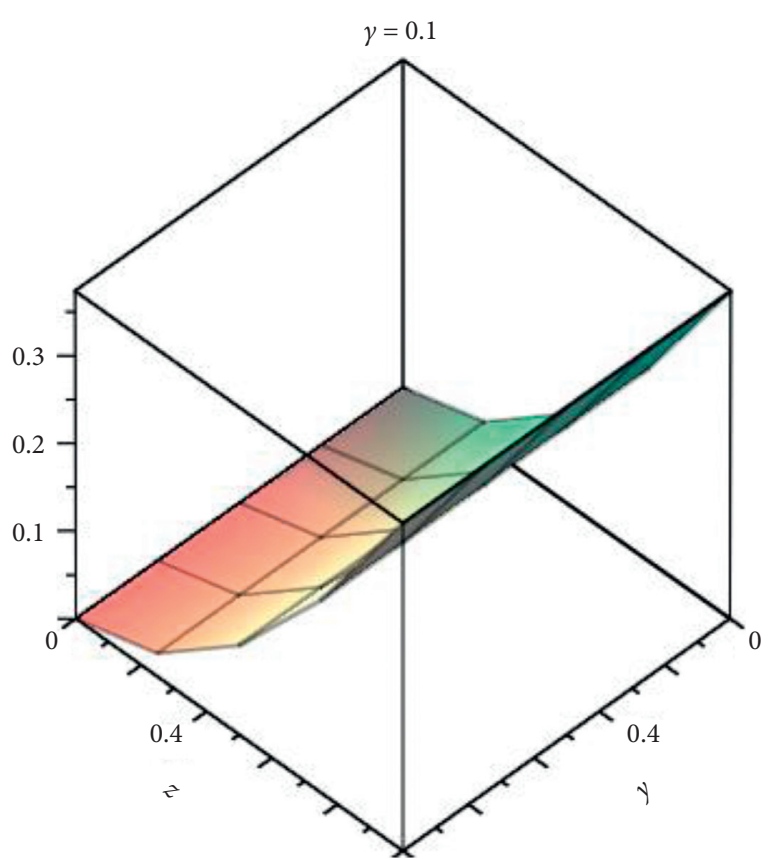

FIgURE 21: The portray of $3-D$ graph of Reynold's model for $\gamma=0.1$

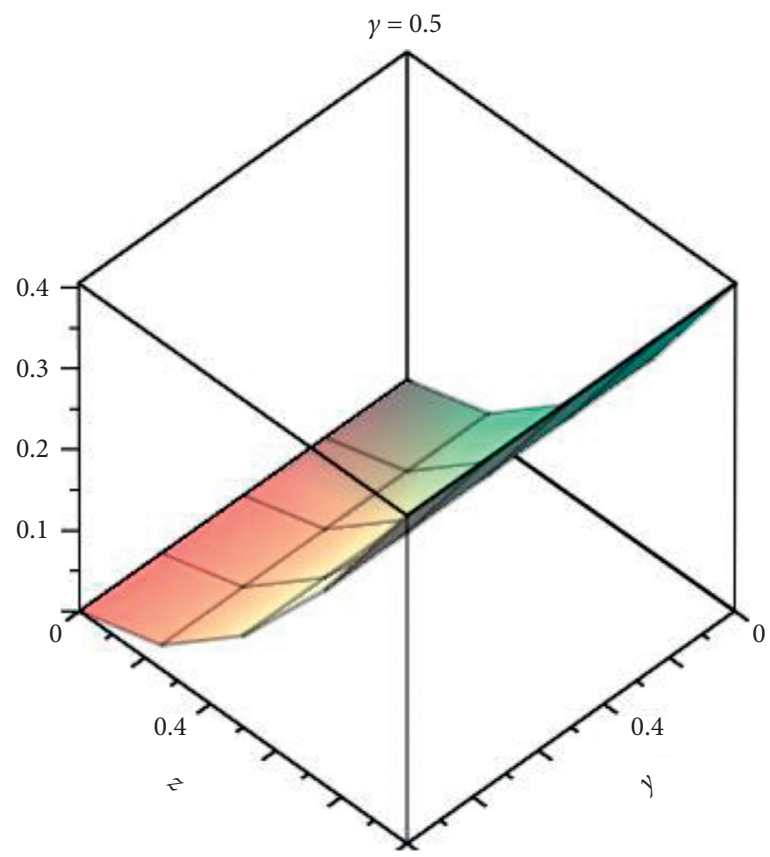

FIgURE 22: The portray of $3-D$ graph of Reynold's model for $\gamma=0.5$

Reynold's model. Figure 14 shows the impact of $\gamma=0.1,0.2,0.3,0.4$ for temperature field of Reynold's model. Figure 15 depicts the influence of $\gamma$ and $N=0.1,0.5,1.0$ for Reynold's model's Nusselt number. Figure 16 represents the impact for Vogel's model on $D=$ $0.1,0.25,0.5$ and $\gamma$ for skin friction. Figure 17 shows effects for Vogel's model on Nusselt number for $\gamma$ and 


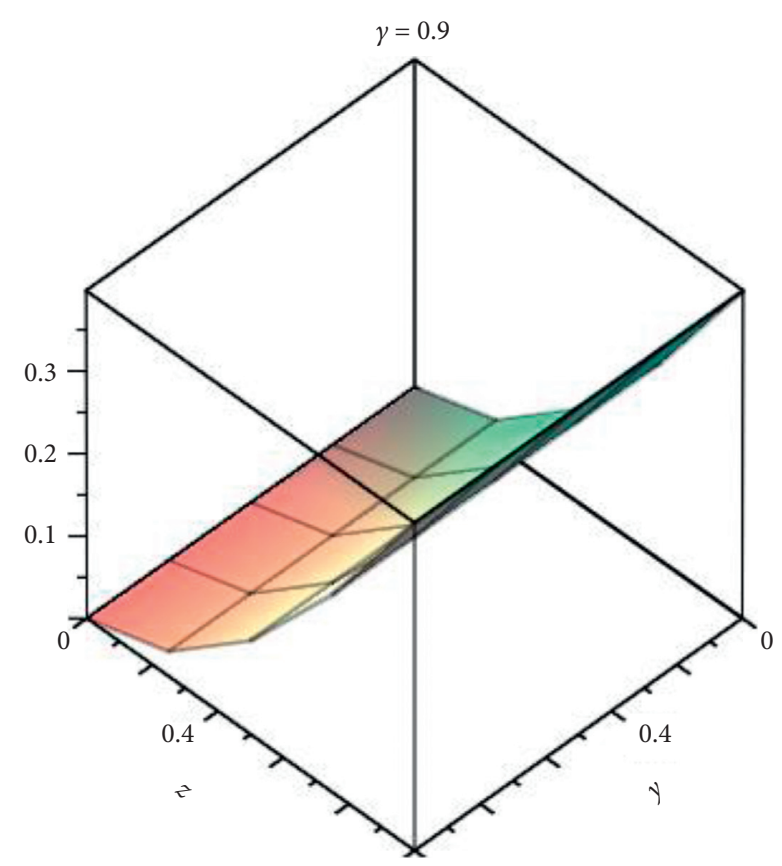

FIGURE 23: The portray of $3-D$ graph of Reynold's model for $\gamma=0.9$

TABLE 1: The values of change in $\gamma$ for temperature of Reynold's model at the wall.

\begin{tabular}{lcccc}
\hline$\gamma$ & 0.1 & 0.2 & 0.3 & 0.4 \\
\hline$N=0.1$ & & & & \\
$R=0.6$ & & & & \\
$\operatorname{Pr}=7.7$ & -0.8769141 & -1.1638242 & $-1: 4937560$ & -1.8544489 \\
$\lambda=1.5$ & & & & \\
$W=0.2$ & & & & \\
\hline
\end{tabular}

TABle 2: The values of change in $W$ for temperature of Reynold's model at the wall.

\begin{tabular}{lcccc}
\hline$W$ & 0.1 & 1.1 & 2.1 & 3.1 \\
\hline$N=0.1$ & & & & \\
$R=0.6$ & & & & \\
$\operatorname{Pr}=7.7$ & -0.8718237 & -0.9246222 & -0.9818317 & -1.04378 \\
$\lambda=1.5$ & & & & \\
$\gamma=0.1$ & & & & \\
\hline
\end{tabular}

TABle 3: The values of change in $R$ for temperature of Reynold's model at the wall.

\begin{tabular}{lcccc}
\hline$R$ & 0.6 & 1.0 & 1.4 & 1.8 \\
\hline$N=0.1$ & & & & \\
$W=0.2$ & & & & \\
$\operatorname{Pr}=7.7$ & -0.8769141 & -0.7838524 & -0.7274551 & -0.6896815 \\
$\lambda=1.5$ & & & & \\
$\gamma=0.1$ & & & & \\
\hline
\end{tabular}

TABLE 4: The values of change in $\lambda$ for temperature of Reynold's model at the wall.

\begin{tabular}{lcccc}
\hline$\lambda$ & 1.5 & 2.0 & 2.5 & 3.0 \\
\hline$N=0.1$ & & & & \\
$W=0.2$ & & & & \\
$\operatorname{Pr}=7.7$ & -0.8769141 & -0.9210312 & -0.9650590 & -1.0089976 \\
$R=1.5$ & & & & \\
$\gamma=0.1$ & & & & \\
\hline
\end{tabular}

TABLe 5: The values of change in Pr for temperature of Reynold's model at the wall.

\begin{tabular}{lcccc}
\hline $\operatorname{Pr}$ & 7.7 & 8.8 & 9.9 & 10.10 \\
\hline$N=0.1$ & & & & \\
$W=0.2$ & & & & \\
$\lambda=2.5$ & -0.9650590 & -1.0069910 & -1.0499959 & -1.0579279 \\
$R=1.5$ & & & & \\
$\gamma=0.1$ & & & & \\
\hline
\end{tabular}

TABle 6: The values of change in $N$ for temperature of Reynold's model at the wall.

\begin{tabular}{lcccc}
\hline$N$ & 0.1 & 0.4 & 0.7 & 1.0 \\
\hline $\operatorname{Pr}=8.8$ & & & & \\
$W=0.2$ & & & & \\
$\lambda=2.5$ & -1.0069910 & -1.0285733 & -1.0497506 & -1.0702968 \\
$R=1.5$ & & & & \\
$\gamma=0.1$ & & & & \\
\hline
\end{tabular}

TABLE 7: The values of change in $\gamma$ for temperature of Vogel's model at the wall.

\begin{tabular}{lcccc}
\hline$\gamma$ & 0.1 & 0.3 & 0.5 & 0.7 \\
\hline$N=1.3$ & & & & \\
$R=0.1$ & & & & \\
$\operatorname{Pr}=7.7$ & -2.9582914 & -4.075563 & -5.3502953 & -6.6967343 \\
$\lambda=1.7$ & & & & \\
$D=1.9$ & & & & \\
$E=2.0$ & & & & \\
$G^{*}=1.8$ & & & & \\
$G=1.1$ & & & & \\
\hline
\end{tabular}

TABLE 8: The values of change in $\lambda$ for temperature of Vogel's model at the wall.

\begin{tabular}{lcccc}
\hline$\lambda$ & 0.7 & 3.3 & 5.9 & 8.5 \\
\hline$N=1.3$ & & & & \\
$R=0.1$ & & & & \\
$\operatorname{Pr}=7.7$ & -4.2929048 & -6.9167525 & -9.1619449 & -11.076930 \\
$\gamma=0.5$ & & & & \\
$D=1.9$ & & & & \\
$E=2.0$ & & & & \\
$G^{*}=1.8$ & & & & \\
$G=1.1$ & & & & \\
\hline
\end{tabular}


TABLe 9: The values of change in Pr for temperature of Vogel's model at the wall.

\begin{tabular}{lcccc}
\hline $\operatorname{Pr}$ & 7.7 & 8.8 & 9.9 & 10.10 \\
\hline$N=1.3$ & & & & \\
$R=0.1$ & & & & \\
$\lambda=1.7$ & -5.3502950 & -5.8292081 & -6.3140881 & -6.4026828 \\
$\gamma=0.5$ & & & & \\
$D=1.9$ & & & & \\
$E=2.0$ & & & & \\
$G^{*}=1.8$ & & & & \\
$G=1.1$ & & & & \\
\hline
\end{tabular}

TABle 10: The values of change in $N$ for temperature of Vogel's model at the wall.

\begin{tabular}{lcccc}
\hline$N$ & 1.4 & 1.5 & 1.6 & 1.7 \\
\hline $\operatorname{Pr}=9.9$ & & & & \\
$R=0.1$ & & & & \\
$\lambda=1.7$ & -6.3140881 & -6.3323518 & -6.3506975 & -6.3691254 \\
$\gamma=0.5$ & & & & \\
$D=1.9$ & & & & \\
$E=2.0$ & & & & \\
$G^{*}=1.8$ & & & & \\
$G=1.1$ & & & & \\
\hline
\end{tabular}

TABLE 11: The values of change in $R$ for temperature of Vogel's model at the wall.

\begin{tabular}{lcccc}
\hline$R$ & 0.4 & 0.5 & 0.6 & 0.7 \\
\hline $\operatorname{Pr}=9.9$ & & & & \\
$N=1.6$ & & & & \\
$\lambda=1.7$ & -6.3506975 & -5.6990981 & -5.1785360 & -4.7545397 \\
$\gamma=0.5$ & & & & \\
$D=1.9$ & & & & \\
$E=2.0$ & & & & \\
$G^{*}=1.8$ & & & & \\
$G=1.1$ & & & & \\
\hline
\end{tabular}

TABLE 12: The values of change in $E$ for temperature of Vogel's model at the wall.

\begin{tabular}{lcccc}
\hline$E$ & 2.0 & 2.4 & 2.8 & 3.2 \\
\hline $\operatorname{Pr}=9.9$ & & & & \\
$N=1.6$ & & & & \\
$\lambda=1.7$ & -5.1785360 & -5.2495374 & -5.2941906 & -5.3239363 \\
$\gamma=0.5$ & & & & \\
$D=1.9$ & & & & \\
$R=0.3$ & & & & \\
$G^{*}=1.8$ & & & & \\
$G=1.1$ & & & & \\
\hline
\end{tabular}

$D=0.1,0.5,1.0$. Figures $18-20$ give the stream lines of $\gamma=$ $0.1,0.5,0.9$ for Reynold's model. Figures $21-23$ tell $3-D$ structures of $\gamma=0.1,0.5,0.9$ for Reynold's model. Tables 1-6 give the change in temperature for Reynold's model on $N, W, R, \gamma, \lambda$ and $P r$ at the wall. Tables 7-15 depict the change in temperature for Vogel's model on $G, D, E, G^{*}, R, N, \gamma, \lambda$ and $\operatorname{Pr}$ at the wall. Table 16 elucidates the ináuence of $N, W, R, \gamma, \lambda$ and $\operatorname{Pr}$ on Nusselt
TABle 13: The values of change in $D$ for temperature of Vogel's model at the wall.

\begin{tabular}{lcccc}
\hline$D$ & 1.9 & 2.4 & 2.9 & 3.4 \\
\hline $\operatorname{Pr}=9.9$ & & & & \\
$N=1.6$ & & & & \\
$\lambda=1.7$ & -5.2941906 & -5.2615104 & -5.2295760 & -5.1983724 \\
$\gamma=0.5$ & & & & \\
$E=2.8$ & & & & \\
$R=0.3$ & & & & \\
$G^{*}=1.8$ & & & & \\
$G=1.1$ & & & & \\
\hline
\end{tabular}

TABLe 14: The values of change in $G^{*}$ for temperature of Vogel's model at the wall.

\begin{tabular}{lcccc}
\hline$G^{*}$ & 1.8 & 2.4 & 3.0 & 3.6 \\
\hline $\operatorname{Pr}=9.9$ & & & & \\
$N=1.6$ & & & & \\
$\lambda=1.7$ & -5.2295760 & -5.3720192 & -5.4587700 & -5.5161120 \\
$\gamma=0.5$ & & & & \\
$E=2.8$ & & & & \\
$R=0.3$ & & & & \\
$D=1.9$ & & & & \\
$G=1.1$ & & & & \\
\hline
\end{tabular}

TABLE 15: The values of change in $G$ for temperature of Vogel's model at the wall.

\begin{tabular}{lcccc}
\hline$G$ & 1.1 & 2.6 & 3.1 & 3.6 \\
\hline $\operatorname{Pr}=9.9$ & & & & \\
$N=1.6$ & & & & \\
$\lambda=1.7$ & -5.4582770 & -5.3018863 & -5.1474593 & -4.9949967 \\
$\gamma=0.5$ & & & & \\
$E=2.8$ & & & & \\
$R=0.3$ & & & & \\
$D=1.9$ & & & & \\
$G^{*}=1.1$ & & & & \\
\hline
\end{tabular}

TABLE 16: Values of Nusselt number for distinct parameters for Reynold's model.

\begin{tabular}{|c|c|c|c|c|c|c|}
\hline$\gamma$ & $\operatorname{Pr}$ & $\lambda$ & $N$ & $W$ & $R$ & $-\theta^{\prime}(0)$ \\
\hline 0.1 & 7.7 & 1.5 & 0.1 & 0.2 & 0.6 & -0.8769141 \\
\hline 0.12 & & & & & & -0.9303180 \\
\hline 0.13 & & & & & & -0.9857684 \\
\hline \multirow[t]{16}{*}{0.1} & & & & & & -0.8769141 \\
\hline & 7.8 & & & & & -0.8857447 \\
\hline & 7.9 & & & & & -0.8982711 \\
\hline & 7.7 & & & & & -0.9019798 \\
\hline & & 1.6 & & & & -0.8857447 \\
\hline & & 1.7 & & & & -0.8945717 \\
\hline & & 1.5 & & & & -0.8769141 \\
\hline & & & 0.2 & & & -0.8998446 \\
\hline & & & 0.3 & & & -0.9051285 \\
\hline & & & 0.1 & & & -0.8769141 \\
\hline & & & & 0.3 & & -0.9055561 \\
\hline & & & & 0.4 & & -0.9113143 \\
\hline & & & & 0.2 & & -0.8769141 \\
\hline & & & & & 0.7 & -0.8697710 \\
\hline & & & & & 0.8 & -0.8438659 \\
\hline & & & & & 0.6 & -0.8769141 \\
\hline
\end{tabular}


TABle 17: Values of Nusselt number for distinct parameters for Vogel's model.

\begin{tabular}{|c|c|c|c|c|c|c|c|c|c|}
\hline$\gamma$ & G & $G^{*}$ & $D$ & $E$ & $N$ & $R$ & $\lambda$ & $\operatorname{Pr}$ & $-\theta^{\prime}(0)$ \\
\hline 0.1 & 1.1 & 1.8 & 1.9 & 2.0 & 1.3 & 0.1 & 1.7 & 7.7 & -2.9582914 \\
\hline 0.12 & & & & & & & & & -3.0601193 \\
\hline 0.13 & & & & & & & & & -3.1119549 \\
\hline \multirow[t]{25}{*}{0.1} & & & & & & & & & -2.9582914 \\
\hline & 1.2 & & & & & & & & -2.9084736 \\
\hline & 1.3 & & & & & & & & -2.8591143 \\
\hline & 1.1 & & & & & & & & -2.9582914 \\
\hline & & 1.9 & & & & & & & -2.9873442 \\
\hline & & 2.0 & & & & & & & -3.0136246 \\
\hline & & 1.8 & & & & & & & -2.9582914 \\
\hline & & & 2.0 & & & & & & -2.9487213 \\
\hline & & & 2.1 & & & & & & -2.9293538 \\
\hline & & & 1.9 & & & & & & -2.9582914 \\
\hline & & & & 2.1 & & & & & -2.9754499 \\
\hline & & & & 2.2 & & & & & -2.9905879 \\
\hline & & & & 2.0 & & & & & -2.9582914 \\
\hline & & & & & 1.4 & & & & -2.9615122 \\
\hline & & & & & 1.5 & & & & -2.9647360 \\
\hline & & & & & 1.3 & & & & -2.9582914 \\
\hline & & & & & & 0.2 & & & -2.7521710 \\
\hline & & & & & & 0.3 & & & -2.5831617 \\
\hline & & & & & & 0.1 & & & -2.9582914 \\
\hline & & & & & & & 1.8 & & -2.8305255 \\
\hline & & & & & & & 1.9 & & -2.9083449 \\
\hline & & & & & & & 1.7 & & -2.9582914 \\
\hline & & & & & & & & 7.8 & -2.6785432 \\
\hline & & & & & & & & 7.9 & -2.8762390 \\
\hline & & & & & & & & 7.7 & -2.9083449 \\
\hline
\end{tabular}

TABle 18: Values of skin friction for distinct parameters for Reynold's model.

\begin{tabular}{|c|c|c|c|c|c|c|}
\hline$N$ & $\lambda$ & $\mathrm{Pr}$ & $\gamma$ & $W$ & $R$ & $(1 / 2) C_{f} \operatorname{Re}$ \\
\hline 0.1 & 1.7 & 7.7 & 0.1 & 0.2 & 0.2 & -0.1616633 \\
\hline 0.2 & & & & & & -0.1683275 \\
\hline 0.3 & & & & & & -0.1749933 \\
\hline \multirow[t]{16}{*}{0.1} & & & & & & -0.1616633 \\
\hline & 1.8 & & & & & -0.1615948 \\
\hline & 1.9 & & & & & -0.1615263 \\
\hline & 1.7 & & & & & -0.1616633 \\
\hline & & 7.8 & & & & -0.1616311 \\
\hline & & 7.9 & & & & -0.1615991 \\
\hline & & 7.7 & & & & -0.1616633 \\
\hline & & & 0.2 & & & -0.0867723 \\
\hline & & & 0.3 & & & -0.0124727 \\
\hline & & & 0.1 & & & -0.1616633 \\
\hline & & & & 0.3 & & -0.9055561 \\
\hline & & & & 0.4 & & -0.1709230 \\
\hline & & & & 0.2 & & -0.1802208 \\
\hline & & & & & 0.3 & -0.1620517 \\
\hline & & & & & 0.4 & -0.1623734 \\
\hline & & & & & 0.2 & -0.1616633 \\
\hline
\end{tabular}

number. Table 17 explicates the consequences of $G, G^{*}, D, E, R, N, \gamma, \lambda$ and Pr for Vogel's model. Table 18 shows the behavior of $N$ and on skin friction coefficient for Reynold's model. Table 19 indicates the consequences of
TABLE 19: Values of skin friction for distinct parameters for Vogel's model.

\begin{tabular}{|c|c|c|c|c|c|c|c|c|c|}
\hline G & $G^{*}$ & $D$ & $\lambda$ & $\gamma$ & $E$ & $\operatorname{Pr}$ & $N$ & $R$ & $(1 / 2) C_{f} \operatorname{Re}$ \\
\hline 2.1 & 0.4 & 0.3 & 0.7 & 0.1 & 2.0 & 7.7 & 1.3 & 0.2 & -22.004282 \\
\hline 2.2 & & & & & & & & & -20.506954 \\
\hline 2.3 & & & & & & & & & -26.049557 \\
\hline 2.1 & & & & & & & & & -22.004282 \\
\hline & 0.5 & & & & & & & & -14.881911 \\
\hline & 0.6 & & & & & & & & -11.134132 \\
\hline & 0.4 & & & & & & & & -22.004282 \\
\hline & & 0.4 & & & & & & & 0.41191405 \\
\hline & & 0.5 & & & & & & & 0.53440194 \\
\hline & & 0.3 & & & & & & & -22.004282 \\
\hline & & & 0.8 & & & & & & -22.004911 \\
\hline & & & 0.9 & & & & & & -22.005536 \\
\hline & & & 0.7 & & & & & & -22.004282 \\
\hline & & & & 0.2 & & & & & -21.968573 \\
\hline & & & & 0.3 & & & & & -21.936179 \\
\hline & & & & 0.1 & & & & & -22.004282 \\
\hline & & & & & 2.1 & & & & 0.24714771 \\
\hline & & & & & 2.2 & & & & 0.21495112 \\
\hline & & & & & 2.0 & & & & -22.004282 \\
\hline & & & & & & 7.8 & & & -22.002875 \\
\hline & & & & & & 7.9 & & & -22.001468 \\
\hline & & & & & & 7.7 & & & -22.004282 \\
\hline & & & & & & & 1.4 & & -22.023073 \\
\hline & & & & & & & 1.5 & & -22.041869 \\
\hline & & & & & & & 1.3 & & -22.004282 \\
\hline & & & & & & & & 0.2 & -22.098766 \\
\hline & & & & & & & & 0.3 & -22.567879 \\
\hline & & & & & & & & 0.1 & -22.004282 \\
\hline
\end{tabular}

$G, D, E, G^{*}, N, \gamma, \lambda$ and Pr for skin friction coefficient of Vogel's model.

\section{Concluding Remarks}

In this inquisition, the numerical solution of Walters' B fluid model with MHD and radiation effects of both time dependent viscosity models has been discussed. Influences of these parameters are presented with the help of graphs and tables. Some important points of the study of this problem are the following:

(1) A sensible growth is seen in the velocity portray as increase in $G$ and the velocity curve decreases with the enlargement of $\gamma, D$ and $N$ for both models

(2) $\gamma$ andPr are decreases for Reynold's well as Vogel's models

(3) The stream lines are sighted to shrink and the $3-D$ graphs bended with the increase in $\gamma$ of Reynold's model

(4) Skin friction curve increases with the increase in $N$, while Nusselt number graph decreases with the enlargement in $\lambda$

\section{Data Availability}

The data used to support the study are available from the corresponding author upon request. 


\section{Conflicts of Interest}

The authors declare that they have no conflicts of interest.

\section{References}

[1] K. R. Rajagopal, T. Y. Na, and A. S. Gupta, "Flow of viscoelastic fluid over a stretching sheet," Rheologica Acta, vol. 23, p. $213215,1984$.

[2] I. Shahzadi, S. Suleman, S. Saleem, and S. Nadeem, "Utilization of $\mathrm{Cu}$-nanoparticles as medication agent to reduce atherosclerotic lesions of a bifurcated artery having compliant walls," Computer Methods and Programs in Biomedicine, vol. 184, Article ID 105123, 2020.

[3] A. U. Khan, S. Saleem, S. Nadeem, and A. A. Alderremy, "Analysis of unsteady non-axisymmetric Homann stagnation point flow of nanofluid and possible existence of multiple solutions," Physica A: Statistical Mechanics \& Its Applications, vol. 554, Article ID 123920, 2020.

[4] A. Hussain, S. Akbar, L. Sarwar, S. Nadeem, and Z. Iqbal, "Effect of time dependent viscosity and radiation efficacy on a non-Newtonian fluid flow," Heliyon, vol. 5, no. 2, Article ID e01203, 2019.

[5] U. Arif, M. Nawaz, S. O. Alharbi, and S. Saleem, "Investigation on the impact of thermal performance of fluid due to hybrid nano-structures," Journal of Thermal Analysis and Calorimetry, vol. 1-9, 2020.

[6] M. Nawaz, U. Nazir, S. Saleem, and S. O. Alharbi, “An enhancement of thermal performance of ethylene glycol by nano and hybrid nanoparticles," Physica A: Statistical Mechanics and Its Applications, vol. 551, p. 124527, 2020.

[7] A. Hussain, L. Sarwar, S. Nadeem, and S. Akbar, "Sarmad Jamal, Inquisition of combined effects of radiation and MHD on elasticoviscous fluid flow past a pervious plate," Journal of the Brazilian Society of Mechanical Sciences and Engineering, vol. 40, p. 343, 2018.

[8] S. Bilal, Khalil-ur-Rehman, M. Y. Malik, A. Hussain, and M. Khan, "Effects of temperature dependent conductivity and absorptive/generative heat transfer on MHD three dimensional flow of Williamson fluid due to bidirectional non-linear stretching surface," Results in Physics, vol. 7, pp. 204-212, 2017.

[9] S. Nadeem, R. U. Haq, and Z. H. Khan, "Numerical study of MHD boundary layer flow of a Maxwell fluid past a stretching sheet in the presence of nanoparticles," Journal of the Taiwan Institute of Chemical Engineers, vol. 45, no. 1, pp. 121-126, 2014.

[10] S. Nadeem, M. Israr-ur-Rehman, and S. Saleem, "Ebenezer Bonyah, Dual solutions in MHD stagnation point flow of nanofluid induced by porous stretching/shrinking sheet with anisotropic slip," AIP Advances, vol. 10, Article ID 065207, 2020.

[11] K. Basant, M. O. Oni, Role of magnetic field on mixed convective flow between two concentric microtubes with heat generation/absorption: an exact solution," Journal of Nanomaterials, Nanoengineering and Nanosystems, vol. 232, pp. 59-67, 2018.

[12] A. Hussain, S. Akbar, L. Sarwar, and M. Y. Malik, "Numerical investigation of squeezing flow of Walters B fluid through parallel plates," Journal of the Brazilian Society of Mechanical Sciences and Engineering, vol. 41, p. 477, 2019.

[13] K. Basant and M. O. Oni, "Theory of fully developed mixed convection including flow reversal: a nonlinear Boussinesq approximation approach," Heat Transfer Asian Research, vol. $48,2019$.

[14] O. Michael, "Oni. Combined effect of heat source, porosity and thermal radiation on mixed convection flow in a vertical annulus: an exact solution," Engineering Science and Technology, an International Journal, vol. 20, no. 2, pp. 518-527, 2017.

[15] S. Saleem, M. Qasim, A. Alderremy, and S. Noreen, "Heat transfer enhancement using different shapes of $\mathrm{Cu}$ nanoparticles in the flow of water based nanofluid," Physica Scripta, vol. 95, no. 5, Article ID 055209, 2020.

[16] Z. Ahmed, A. Alqahtani, A. Al-Qahtani, S. Nadeem, and S. Saleem, "Computational study of MHD Nanofluid flow possessing micro-rotational inertia over a curved surface with variable thermophysical properties," Processes, vol. 7, no. 6, p. 387, 2019.

[17] M. Y. Malik, M. Khan, and T. Salahuddin, "Imad khan, variable viscosity and MHD flow in casson fluid with cattaneo christov heat ux model using keller box method, engineering science and technology," An International Journal, vol. 19, pp. 1985-1992, 2016.

[18] R. Ellahi, M. Raza, and K. Vafai, "Series solutions of nonNewtonian nano fluids with Reynolds model and Vogels model by means of the homotopy analysis method," Mathematical and Computer Modelling, vol. 55, p. 1876, 1891.

[19] A. Hussain, L. Sarwar, S. Akbar, S. Nadeem, and S. Jamal, "Numerical investigation of viscoelastic nanofluid flow with radiation effects," Journal of Nanomaterials, Nanoengineering and Nanosystems, vol. 23, 2019.

[20] M. Y. Malik, S. Bilal, T. Salahuddin, and K. U. Rehman, "Three-dimensional williamson fluid flow over a linear stretching surface," Mathematical Sciences Letters, vol. 6, no. 1, pp. 53-61, 2017.

[21] R. Ellahi and A. Riaz, "Analytical solutions for MHD flow in a third-grade fluid with variable viscosity," Mathematical and Computer Modelling, vol. 52, p. 1783, 2017.

[22] A. Hussain, M. Y. Malika, T. Salahuddinb, S. Bilal, and M. Awais, "Combined effects of viscous dissipation and Joule heating on MHD Sisko nano fluid over a stretching cylinder," Journal of Molecular Liquids, vol. 231, pp. 341-352, 2016.

[23] T. Salahuddin, M. Y. Malik, A. Hussain, M. Awais, I. Khan, and M. Khan, "Analysis of tangent hyperbolic nanofluid impinging on a stretching cylinder near the stagnation point," Results in Physics, vol. 7, pp. 426-434, 2017.

[24] I. Khan, F. Ali, S. Shafie, and M. Qasim, "Unsteady free convection flow in a Walters -B fluid and heat transfer analysis," Bulletin of the Malaysian Mathematical Sciences Society, vol. 37, no. 2, pp. 437-448, 2014.

[25] C. Y. Wang and C.-O. Ng, "Natural convection in a vertical slit micro-channel with super-hydrophobic slip and temperature jump," ASME J. Heat Transfer, vol. 136, Article ID 034502, 2014.

[26] M. J. Uddin, O. A. Bég, and M. N. Uddin, "Energy conversion under conjugate conduction, magneto-convection, diffusion and nonlinear radiation over a non-linearly stretching sheet with slip and multiple convective boundary conditions," Energy, vol. 115, pp. 1119-1129, 2016.

[27] O. D. Makinde and I. L. Animasaun, "Thermophoresis and Brownian motion effects on MHD bioconvection of nano fluid with nonlinear thermal radiation and quartic chemical reaction past an upper horizontal surface of a paraboloid of revolution," Journal of Molecular Liquids, vol. 221, p. 733 43, 2014. 
[28] I. Khan, K. Fakhar, and M. I. Anwar, "Hydromagnetic rotating flows of an oldroyd-B fluid in a porous medium," Special Topics and Reviews in Porous Media, vol. 3, no. 1, 2012.

[29] S. K. Khan, M. S. Abel, and R. M. Sonth, "Visco-elastic MHD flow, heat and mass transfer over a porous stretching sheet with dissipation of energy and stress work," Heat and Mass Transfer, vol. 40, no. 1-2, pp. 47-57, 2003.

[30] M. M. Nandeppanavar, M. S. Abel, and J. Tawade, "Heat transfer in a Walter s liquid B fluid over an impermeable stretching sheet with non-uniform heat source/sink and elastic deformation," Communications in Nonlinear Science and Numerical Simulation, vol. 15, no. 7, 2010.

[31] K. V. Prasad, M. Subhas Abel, and S. K. Khan, "Momentum and heat transfer in visco-elastic fluid flow in a porous medium over a non-isothermal stretching sheet," International Journal of Numerical Methods for Heat \& Fluid Flow, vol. 10, no. 8, pp. 786-801, 2000.

[32] I. J. Uwanta, B. Y. Isah, and M. O. Ibrahim, "Viscoelastic fluid flow past an infinite vertical plate with heat dissipation," International Journal of Computer Applications, vol. 36, 2011.

[33] O. Prakash, D. Kumar, and Y. K. Dwivedi, "Effects of thermal diffusion and chemical reaction on mhd flow of dusty viscoelastic (walter's liquid model-B) fluid," Journal of Electromagnetic Analysis and Applications, vol. 2, no. 10, pp. 581-587, 2010.

[34] A. K. Abdul Hakeem, N. Vishnu Ganesh, and B. Ganga, "Effect of heat radiation in a Walter's liquid B fluid over a stretching sheet with non-uniform heat source/sink and elastic deformation," Journal of King Saud University - Engineering Sciences, vol. 26, no. 2, pp. 168-175, 2014.

[35] G. Kalpana, "Thermal effect on unsteady flow of a dusty viscoelastic fluid between two parallel plates under different pressure gradients," International Journal of Engineering \& Technology, vol. 2, p. 88, 2013.

[36] M. Khan, M. Y. Malik, T. Salahuddin, and I. Khan, "Heat transfer squeezed flow of Carreau fluid over a sensor surface with variable thermal conductivity: A numerical study," Results in Physics, vol. 6, pp. 940-945, 2016.

[37] A. Hussain, M. Y. Malik, S. Bilal, M. Awais, and T. Salahuddin, "Computational analysis of magnetohydrodynamic Sisko fluid flow over a stretching cylinder in the presence of viscous dissipation and temperature dependent thermal conductivity," Results in Physics, vol. 7, pp. 139-146, 2017.

[38] A. Hussain, M. Y. Malik, T. Salahuddin, S. Bilal, and M. Awais, "Combined effects of viscous dissipation and Joule heating on MHD Sisko nanofluid over a stretching cylinder," Journal of Molecular Liquids, vol. 231, pp. 341-352, 2017. 